\title{
Efficacy of pectin solution for preventing gastro-esophageal reflux events in patients with percutaneous endoscopic gastrostomy
}

\author{
Kyoichi Adachi, ${ }^{1, *}$ Kenji Furuta, ${ }^{2}$ Masahito Aimi, ${ }^{2}$ Kousuke Fukazawa, ${ }^{2}$ Shino Shimura, ${ }^{2}$ Shunji Ohara, ${ }^{2}$ \\ Shuji Nakata, ${ }^{2}$ Yukiko Inoue, ${ }^{3}$ Kanji Ryuko, ${ }^{3}$ Junichi Ishine, ${ }^{3}$ Kyoko Katoh, ${ }^{3}$ Toshiaki Hirata, $^{3}$ Shuzo Ohhata, ${ }^{3}$ \\ Setsushi Katoh, ${ }^{3}$ Mika Moriyama, ${ }^{1}$ Masuko Sumikawa, ${ }^{1}$ Mari Sanpei ${ }^{1}$ and Yoshikazu Kinoshita ${ }^{2}$
}

'Department of Clinical Nursing and 2 Second Department of Internal Medicine, Shimane University Faculty of Medicine, 89-1 Enya-cho, Izumo-shi, Shimane 693-8501, Japan

${ }^{3}$ Katoh Hospital, 383-1 Kawamoto, Kawamoto-cho, Shimane 696-0001, Japan

(Received 11 May, 2011; Accepted 24 June, 2011)

\begin{abstract}
The aim of this study was to determine the efficacy of pectin solution, which increases the viscosity of liquid nutrient, for prevention of gastro-esophageal reflux in comparison with halfsolid nutrient. The subjects were 10 elderly patients undergoing percutaneous endoscopic gastrostomy feeding. Twenty-four-hour esophageal multichannel intraluminal impedance and $\mathrm{pH}$ testing was performed during intake of half-solid nutrient and a combination of pectin solution and liquid nutrient. During $4 \mathrm{~h}$ after delivery, there was no significant difference in the total number of gastro-esophageal reflux events between the feeding of the half-solid nutrient and the combination of pectin solution and liquid nutrient $(5.7 \pm 1.2$ vs $5.3 \pm 1.0 / 4 \mathrm{~h})$. Acidic reflux after delivery of the half-solid nutrient was significantly more frequent than that after delivery of the combination of pectin solution and liquid nutrient $(80.7 \%$ vs $60.4 \%, p=0.018)$. The incidence of gastroesophageal reflux reaching the upper portion of the esophagus tended to be higher during delivery of the half-solid nutrient than during delivery of the combination of pectin solution and liquid nutrient $(47.4 \%$ vs $34.0 \%, p=0.153)$. In conclusion, the usage of pectin solution combined with liquid nutrient is effective for preventing acidic gastro-esophageal reflux and gastro-esophageal reflux reaching the upper portion of the esophagus.
\end{abstract}

Key Words: percutaneous endoscopic gastrostomy, half-solidification, aspiration pneumonitis, pH monitoring, impedance

$\mathrm{P}$ ercutaneous endoscopic gastrostomy (PEG) tube feeding is widely used for patients with swallowing dysfunction caused by a number of disease conditions or a history of repeated aspiration pneumonitis. Aspiration pneumonitis caused by reflux of gastric contents including nutrients supplied via PEG is one of the most frequent and life-threatening events during long-term PEG feeding. ${ }^{(1-4)}$ Solidification of nutrients is considered to be an effective method for preventing gastro-esophageal reflux (GER) of such nutrients, and several studies have demonstrated that increasing their viscosity reduces the risk of GER in infants, based mainly on the number and frequency of regurgitation and vomiting. ${ }^{(5-7)}$ Kanie and coworkers ${ }^{(8)}$ previously demonstrated that half-solidification of nutrient was useful for decreasing GER in patients receiving PEG nutrition. Therefore, half-solidification of nutrients has been widely used to prevent aspiration pneumonitis in patients undergoing PEG feeding in Japan, although the efficacy of this approach has not been fully determined. We recently demonstrated that the use of half-solid nutrients reduces the proportion of observational days when patients have fever in comparison with the use of liquid nutrients. ${ }^{(9)}$ The use of highly thickened nutrient via PEG might effectively prevent GER of the nutrient itself. However, the most effective method for half-solidification of nutrient and the optimal viscosity of half-solid nutrient for preventing GER events, including GER of gastric acid, have not been fully investigated.

Pectin solution is reported to increase the viscosity of liquid nutrient even when it is infused separately into the stomach when liquid nutrient is being supplied.(10-12) The combined usage of pectin solution with liquid nutrient has been reported to prevent GER of liquid nutrient and diarrhea induced by rapid infusion of nutrients in patients undergoing PEG feeding. ${ }^{(10,11)}$ However, the efficacy of pectin solution for prevention of GER has not yet been investigated in comparison with the usage of half-solid nutrient with high viscosity.

Combined multichannel intraluminal impedance (MII) and $\mathrm{pH}$ (MII-pH) testing is the best clinically available tool for monitoring of GER. ${ }^{(13,14)}$ MII monitoring can detect reflux episodes independent of their $\mathrm{pH}$ by measuring the resistance of the intraluminal content to alternating current (i.e., impedance). This makes it possible to characterize the physical composition of the refluxate (i.e., liquid, gas, or mixed) and, when combined with $\mathrm{pH}$ monitoring, to separate acid from non-acid reflux episodes based on predefined $\mathrm{pH}$ criteria. ${ }^{(13,14)}$ Thus, all types of reflux episodes can be evaluated by the MII-pH monitoring system. The aim of this study was to clarify the efficacy of combined usage of pectin solution with liquid nutrient for preventing GER events in patients receiving PEG nutrition in comparison with the use of half-solid nutrient with high viscosity.

\section{Subjects and Methods}

The subjects were 10 elderly patients undergoing PEG feeding (7 females; overall mean age 82.0 years) at Katoh Hospital, Shimane, Japan. PEG feeding had been started because of swallowing dysfunction resulting from cerebral infarction or cerebral bleeding, and the duration of PEG feeding had exceeded one year in all cases. None of the subjects had a history of upper gastrointestinal surgery, or were taking regular medications known to influence upper gastro-intestinal motor function. Four of 10 study subjects were taking anti-secretory drugs, such as proton pump

*To whom correspondence should be addressed.

E-mail: kadachi@med.shimane-u.ac.jp 

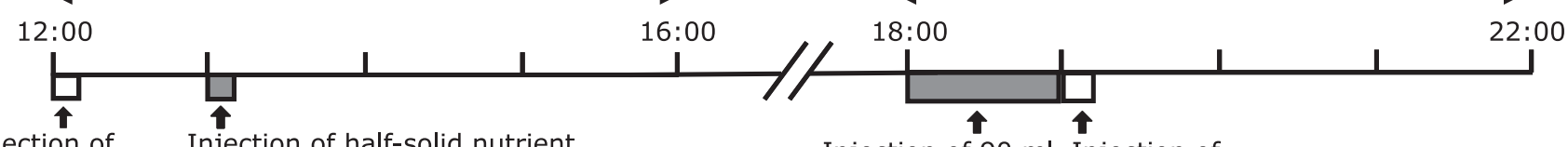

Injection of Injection of half-solid nutrient

$250 \mathrm{ml}$ of water and $20 \mathrm{ml}$ of water

bed head elevation
to $30^{\circ}$

Injection of $90 \mathrm{ml}$ Injection of of pectin solution $60 \mathrm{ml}$ of water and infusion of $300 \mathrm{ml}$ of liquid nutrient

$\stackrel{\text { bed head elevation }}{\text { to } 30^{\circ}}$

b

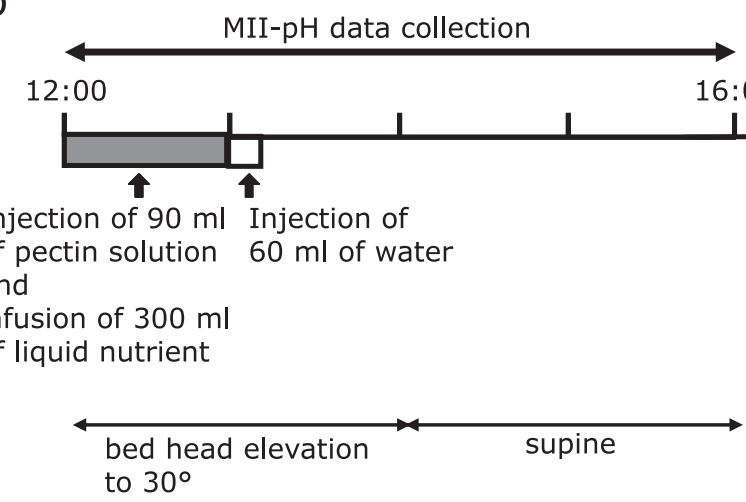

Fig. 1. Nutrient administration schedule (a: half-solid nutrient first and then pectin solution and liquid nutrient protocol for 5 patients, and b: pectin solution and liquid nutrient first and then a half-solid meal protocol for 5 patients).

inhibitors and $\mathrm{H}_{2}$ receptor antagonists. In these 4 patients, 24-h esophageal MII-pH monitoring was performed after withdrawal of all anti-secretory drugs for 7 days in order to completely eliminate their influence. A 24-h esophageal monitoring study during PEG feeding was performed from 7:00 AM using a MII-pH system (Sandhill Scientific Inc., Highlands Ranch, CO). We used a 2.1mm-diameter, combined MII-pH catheter (Sandhill Scientific Inc.) with six impedance and two (esophageal and gastric) antimony $\mathrm{pH}$ sensors with an external reference. Prior to the procedure, the $\mathrm{pH}$ sensors were calibrated using solution buffered at pH 4.0 and 7.0, as specified by the manufacturer. The probe was then inserted transnasally through the esophagus into the stomach, and the esophageal $\mathrm{pH}$ sensor was positioned $5 \mathrm{~cm}$ above the lower esophageal sphincter (LES) under X-ray fluoroscopy guidance. The design of the probe allowed measurement of impedance data at $3,5,7,9,15$, and $17 \mathrm{~cm}$ above the LES. The catheter was connected to a data logger (Sleuth System; Sandhill Scientific Inc.) that stored data from the eight channels (6 impedance and 2 $\mathrm{pH})$ with a frequency of $50 \mathrm{~Hz}$.

After insertion of the MII-pH catheter, conventionally employed liquid nutrient was injected as a breakfast. Half-solid nutrient for lunch and a combination of pectin solution and liquid nutrient for dinner were supplied through PEG tubing in 5 patients, and combined pectin solution and liquid nutrient for lunch and halfsolid nutrient for dinner were supplied in the remaining 5 patients. In this study, we employed commercially available half-solid nutrients and liquid nutrients. The half-solid nutrient was $200 \mathrm{~g}$ of PGSOFT-EJ $^{\circledR}$ (Terumo Corporation, Tokyo, Japan), and the liquid nutrient with pectin solution was $300 \mathrm{ml}$ of K-LEC ${ }^{\circledR}$ (Kewpie Corporation, Tokyo, Japan). Total calories, protein, and lipids in
$200 \mathrm{~g}$ of PGSOFT-EJ ${ }^{\circledR}$ and $300 \mathrm{ml}$ of K-LEC ${ }^{\circledR}$ are $300 \mathrm{kcal}$ and $300 \mathrm{kcal}, 12.0 \mathrm{~g}$ and $10.5 \mathrm{~g}$, and $6.6 \mathrm{~g}$ and $9.9 \mathrm{~g}$, respectively. The contents of several minerals and vitamins in the two nutrients were almost equal. The pectin solution was one pack of REF-P1 ${ }^{\circledR}$ (Kewpie Corporation) for $300 \mathrm{ml}$ of $\mathrm{K}-\mathrm{LEC}^{\circledR}$. One pack of REF$\mathrm{P} 1{ }^{\circledR}$ weighs $90 \mathrm{~g}$ and the content includes $87.3 \mathrm{~g}$ of water, $2.5 \mathrm{~g}$ of pectin, $0.2 \mathrm{~g}$ of protein, $0.1 \mathrm{~g}$ of fat, $0.5 \mathrm{~g}$ of carbohydrate and $1.4 \mathrm{~g}$ of fiber, allowing easy infusion into the stomach using a syringe. The water volumes of PGSOFT-EJ ${ }^{\circledR}$ and the combination of K-LEC ${ }^{\circledR}$ and REF-P $1^{\circledR}$ were markedly different $(131 \mathrm{~g}$ vs $342 \mathrm{~g}$ ). Total water administration was therefore adjusted to $400 \mathrm{~g}$ by modifying the volume of water administered with the nutrients, as described in Fig. 1. The viscosity of PGSOFT-EJ ${ }^{\circledR}$ is about $20000 \mathrm{mPas}$ and that of the combination of K-LEC ${ }^{\circledR}$ and REF-P $1^{\circledR}$ is about $1520 \mathrm{mPas}$, as detailed in the explanatory pamphlet supplied by each manufacturer. PGSOFT-EJ ${ }^{\circledR}$ and the combination of K-LEC ${ }^{\circledR}$ and REF-P1 ${ }^{\circledR}$ were supplied to the patients in accordance with the schedule shown in Fig. 1. Two hundred and fifty millilitres of water was delivered via the PEG feeding tube during a 10-min period before administration of the half-solid nutrient. At $1 \mathrm{~h}$ after delivery of the water, the half-solid nutrient was delivered with $20 \mathrm{ml}$ of water through the PEG tube during a 10-min period. The patients were instructed to remain supine, and the bed head was elevated to $30^{\circ}$ for $2 \mathrm{~h}$. For administration of the combination of pectin solution and liquid nutrient, $90 \mathrm{ml}$ of REF-P $1^{\circledR}$ was injected via the PEG feeding tube using a syringe, and $300 \mathrm{ml}$ of the liquid nutrient was infused by drip infusion during a 1-h period, followed by delivery of $60 \mathrm{ml}$ water during $10 \mathrm{~min}$. Patients were instructed to remain supine, and the bed head was elevated to $30^{\circ}$ for $2 \mathrm{~h}$. 
After 24-h esophageal MII-pH monitoring, the MII-pH data were downloaded and analyzed using dedicated software (BioView Analysis; Sandhill Scientific Inc.). In this study, the numbers of GER events were counted for $4 \mathrm{~h}$ from the start of water infusion at the time of delivery of the half-solid nutrient and from the start of infusion of nutrient at the time of delivery of pectin solution and liquid nutrient. A computerized algorithm (Autoscan; Sandhill Scientific Inc.) was used to identify reflux episodes as changes in impedance progressing in time from the distal to the proximal esophagus. The tracings were subsequently reviewed manually by the investigators to ensure that the automated algorithm correctly identified reflux episodes. Reflux episodes were classified as: (a) liquid-only, if there was only a decrease in impedance progressing distally to proximally; (b) gas-only, if there was only a rise in impedance above 3,000 Ohms in at least two channels progressing distally to proximally; and (c) mixed (gas-liquid or liquid-gas), if there was a combination of the liquid and gas impedance patterns. ${ }^{(13,14)}$ Gas-only reflux episodes were not included in the analysis, and the total number of liquid-only and mixed reflux events was calculated, since liquid-only reflux was observed less frequently than mixed reflux. Reflux episodes were further classified as: (a) acid, if a $\mathrm{pH}$ nadir of less than 4.0 was recorded during the MII-detected reflux patterns; (b) weakly acidic, if the nadir $\mathrm{pH}$ was between 4.0 and 7.0 ; and (c) non-acidic, if the nadir $\mathrm{pH}$ was above $7.0 .^{(13,14)}$ In addition, any reflux extending as far as the most proximal impedance probe at $17 \mathrm{~cm}$ above the LES was also counted. The numbers of each type of reflux event after the two kinds of meals - half-solid and the combination of pectin solution and liquid nutrient-were compared.

Data were expressed as mean $\pm \mathrm{SE}$. Statistical analysis was performed using the Wilcoxon signed rank test and chi-squared test, and differences at $p<0.05$ were considered to be statistically significant.

This study was approved by the local Ethics Committee of Katoh Hospital, and written informed consent was obtained from the patients or their family members.

\section{Results}

All of the 10 participants completed the study protocol without any adverse events. There was no significant difference in the total number of GER events during $4 \mathrm{~h}$ after delivery of the half-solid nutrient and the combination of pectin solution and liquid nutrient $(5.7 \pm 1.2$ vs $5.3 \pm 1.0 / 4 \mathrm{~h}, p=0.678)$. The mean numbers of acid reflux, weakly acidic reflux and non-acidic reflux events after delivery of the half-solid nutrient and liquid nutrient were $3.2 \pm 1.1$ and $2.4 \pm 0.9 / 4 \mathrm{~h}(p=0.345), 1.4 \pm 0.7$ and $0.8 \pm 0.4 / 4 \mathrm{~h}$ $(p=0.075)$, and $1.1 \pm 0.5$ and $2.1 \pm 0.6 / 4 \mathrm{~h}(p=0.208)$, respectively (Fig. 2). The number of acid reflux events after delivery of the half-solid nutrient tended to be higher than that after delivery of the combination of pectin solution and liquid nutrient. When the total reflux events in the 10 subjects were analyzed by dividing them into acidic (acid and weakly acidic) reflux and non-acidic reflux, acidic reflux was significantly more frequent after delivery of the half-solid nutrient than that after delivery of the combination of pectin solution and liquid nutrient $(80.7 \%$ vs $60.4 \%$, $p=0.018)$. The incidence of GER events, extending as far as the most proximal impedance probe, tended to be higher during delivery of the half-solid nutrient than during delivery of the combination of pectin solution and liquid nutrient $(47.4 \%$ vs $34.0 \%, p=0.153)$.

Time course changes in reflux events during the $4 \mathrm{~h}$ after meals are shown in Fig. 3. The number of reflux events after delivery of the half-solid nutrient tended to be higher than after delivery of the

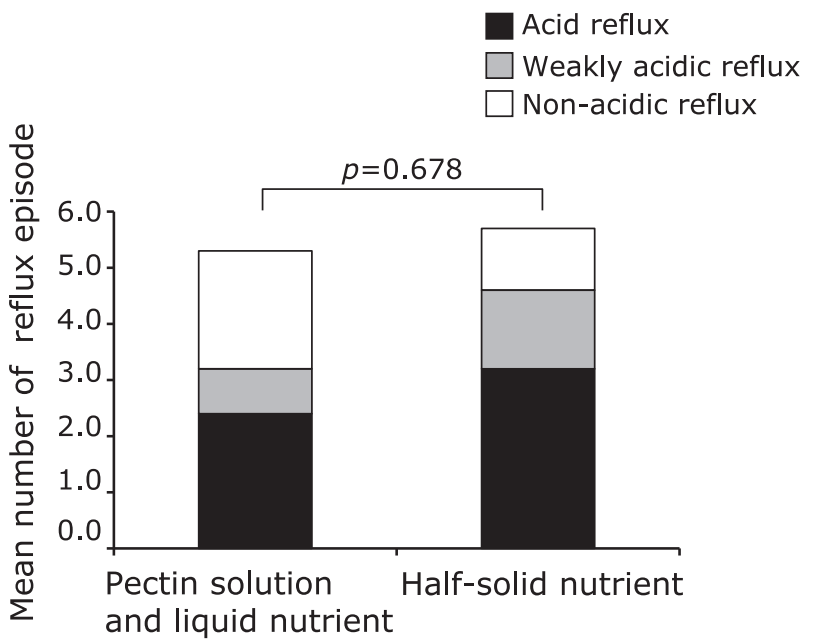

Fig. 2. Total number of gastroesophageal reflux events during $4 \mathrm{~h}$ after the start of feeding.

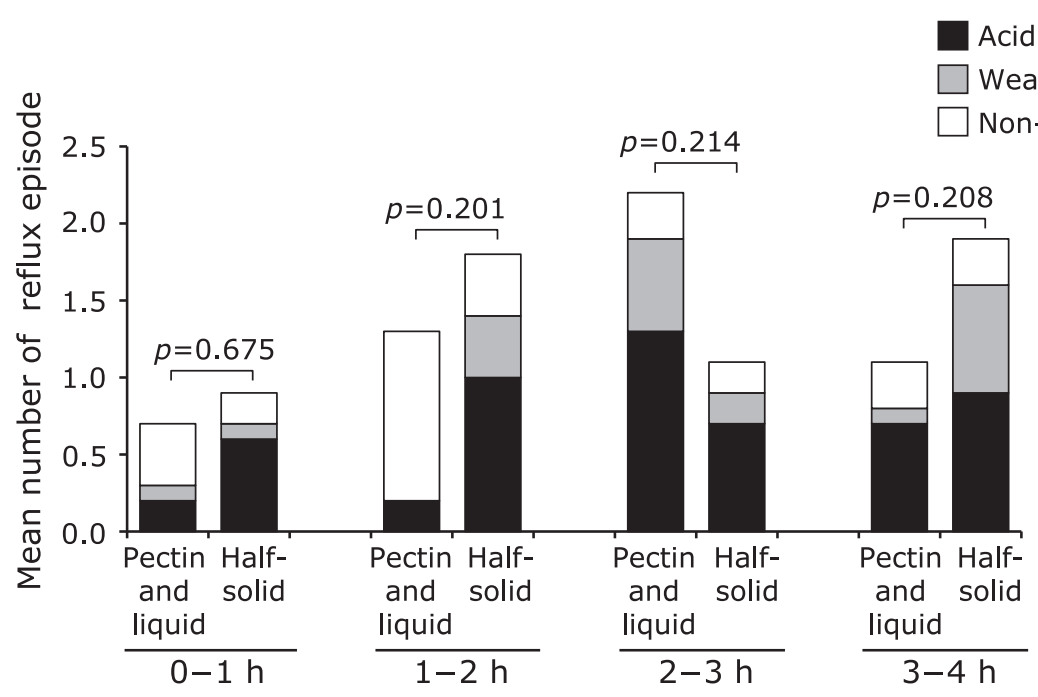

Fig. 3. Time-course of gastroesophageal reflux events after the start of feeding. 
combination of pectin solution and liquid nutrient during the first $2 \mathrm{~h}$ after the start of feeding. GER events associated with delivery of the combination of pectin solution and liquid nutrient were observed most frequently at $1-2 \mathrm{~h}$ after the end of feeding.

\section{Discussion}

PEG tube feeding is widely used for patients with swallowing dysfunction caused by a number of disease conditions. Survival after PEG placement is reported to be influenced by several factors, such as advanced age, complicated diseases and presence of malnutrition before PEG placement. ${ }^{(15-17)}$ Aspiration pneumonitis caused by reflux of gastric contents is also demonstrated to affect the survival in patients with long-term PEG feeding. ${ }^{(1-4,18,19)}$ Half-solidification or increased viscosity of a nutrient have been demonstrated to be effective for decreasing GER of the nutrient. ${ }^{(8,10,11)}$ In this study using the MII-pH method, we made a comparison of GER events associated with the use of half-solid nutrient with relatively high viscosity and a combination of pectin solution and liquid nutrient in patients undergoing PEG feeding. The results of this study showed that the use of liquid nutrient with pectin solution was able to decrease acidic GER in comparison with half-solid nutrient, although there was no significant difference in the total number of reflux events between the two nutrient delivery methods. Previously, Fletcher and colleagues had demonstrated that there was a zone of apparently unbuffered highly acidic gastric juice above the ingested food at 15 min after a meal, a phenomenon that they termed an "acid pocket". ${ }^{(20)}$ The median $\mathrm{pH}$ in this zone was 1.6 , compared with 4.4 in the meal-buffered region in the stomach, and this was considered an important cause of postprandial acidic GER. ${ }^{(20)}$ In addition, the acid pocket in patients with GER has been demonstrated to persist for longer than in healthy volunteers, remaining highly acidic for up to $2 \mathrm{~h}$ postprandially relative to the body of the stomach. The zone of acidic gastric juice after delivery of half-solid nutrient with high viscosity may be wider than that after liquid nutrient, since gastric juice could become easily mixed with liquid nutrient. Indeed, we have previously demonstrated that the number of acid reflux events after half-solid nutrient feeding tended to be higher than that after liquid nutrient feeding. ${ }^{(21)}$ In contrast to the delivery of half-solid nutrient with high viscosity, pectin solution can be easily infused into the stomach via the PEG tube and increase the viscosity of intragastric liquid nutrient. It is also considered to reduce the width of the acid pocket, since the solution can also easily mix with the gastric acidic liquid contents. GER of highly acidic gastric contents has been reported to cause severe aspiration pneumonitis. ${ }^{(2)}$ Therefore, the use of pectin solution with liquid nutrient may effectively reduce the incidence of aspiration pneumonitis caused by GER events in comparison with half-solid nutrient. The results of this study also demonstrated that the use of pectin solution and liquid nutrient might decrease the incidence of GER extending as far as the upper portion of the esophagus in comparison with half-solid nutrient. The viscosity of reflux contents after the feeding of pectin solution and liquid nutrient may be higher than that after the feeding of half-solid nutrient, since the viscosity is important factor to influence the volume and speed of reflux contents.

\section{References}

1 Coben RM, Weintraub A, DiMarino AJ Jr., Cohen S. Gastroesophageal reflux during gastrostomy feeding. Gastroenterology 1994; 106: 13-18.

2 Marik PE. Aspiration pneumonitis and aspiration pneumonia. $N$ Engl J Med 2001; 344: 665-671.

3 Sanders DS, Carter MJ, D'Silva J, McAlindon ME, Willemse PJ, Bardham KD. Percutaneous endoscopic gastrostomy: a prospective analysis of hospital support required and complications following discharge to the community.
The pattern of the changes in GER with time showed a difference between delivery of the half-solid nutrient and the combination of pectin solution and liquid nutrient. Acidic GER was frequently observed after injection of $300 \mathrm{ml}$ water and after the injection of half-solid nutrient. This indicated that both liquid and half-solid materials easily cause frequent GER when they are infused quickly. The number of weakly acidic GER events increased markedly from 2 to $3 \mathrm{~h}$ after the start of delivery of pectin solution and liquid nutrient. This time point corresponded to that when the bed head was returned from an elevated to a flat position. GER at this time point may be caused by the remaining mixture of liquid nutrient and acidic gastric juice in the stomach even $1 \mathrm{~h}$ after the completion of liquid nutrient delivery, and GER of retained liquid gastric contents could be easily induced by this postural change. Gastric emptying associated with combined delivery of pectin solution and liquid nutrient should be investigated in a future study in comparison with half-solid nutrient.

There are some limitations in this study. The number of study subjects was relatively small. In addition, we did not compare GER events during administration of liquid nutrient with and without the usage of pectin solution, although the combined usage of pectin solution with liquid nutrient has been reported to prevent GER of liquid nutrient in patients undergoing PEG feeding. ${ }^{(10,11)}$ In this study, the order in which the water and the nutrient were given differed for each nutrient dosage. Water was administered $60 \mathrm{~min}$ before administration of the half-solid nutrient to retain the viscosity and small volume of the latter. On the other hand, water was administrated after administration of the pectin solution and liquid nutrient to further increase the intragastric volume. We examined GER events using the MII-pH method, which can detect all types of GER. However, this method did not allow investigation of GER volume, which may be one of the most important factors associated with the occurrence of aspiration pneumonitis. Therefore, a further prospective long-term study should be performed to clarify the efficacy of pectin solution in combination with liquid nutrient for preventing the occurrence of aspiration pneumonitis.

In conclusion, delivery of liquid nutrient with pectin solution, REF-P1 ${ }^{\circledR}$, is able to reduce the incidence of both acidic GER and GER that extends as far as the upper portion of the esophagus, in comparison with half-solid nutrient with high viscosity, during PEG feeding.

\section{Acknowledgment}

This study was supported by the funding from the Grants-inAid from Science Research from the Ministry of Education, Culture, Sports, Science and Technology of Japan, No. 22590681. None of the authors had a personal or financial conflict of interest.

\section{Abbreviations}

GER gastro-esophageal reflux

LES lower esophageal sphincter

MII multichannel intraluminal impedance

MII-pH multichannel intraluminal impedance and $\mathrm{pH}$

PEG percutaneous endoscopic gastrostomy
Eur J Clin Nutr 2001; 55: 610-614

4 Carnes ML, Sabol DA, DeLegge M. Does the presence of esophagitis prior to PEG placement increase the risk for aspiration pneumonia? Dig Dis Sci 2004; 49: 1798-1802.

5 Penna FJ, Norton RC, Carvalho AS, et al. Comparison between pre-thickened and home-thickened formulas in gastroesophageal reflux treatement. $J$ Pediatr (Rio J) 2003; 79: 49-54. 
6 Wenzl TG, Schneider S, Scheele F, Silny J, Heimann G, Skopnik H. Effects of thickened feeding on gastroesophageal reflux in infants: a placebo-controlled crossover study using intraluminal impedance. Pediatrics 2003; 111 (4 Pt 1): e355-e359.

7 McPherson V, Wright ST, Bell AD. Clinical inquiries. What is the best treatment for gastroesophageal reflux and vomiting in infants? J Fam Pract 2005; 54: 372-375.

8 Kanie J, Suzuki Y, Iguchi A, Akatsu H, Yamamoto T, Shimokata H. Prevention of gastroesophageal reflux using an application of half-solid nutrients in patients with percutaneous endoscopic gastrostomy feeding. $\mathrm{J} \mathrm{Am}$ Geriatr Soc 2004; 52: 466-467.

9 Shizuku T, Adachi K, Furuta K, et al. Efficacy of half-solid nutrient for the elderly patients with percutaneous endoscopic gastrostomy. J Clin Biochem Nutr 2011; 48: 226-229.

10 Tabei I, Kubo H, Yano F, Inada H. The effect of viscosity regulating solution for enteral nutrition against gastroesophageal reflux (in Japanese with English abstract). Jpn J Gastroenterol Surg 2003; 36: 71-77.

11 Tabei I, Inada $\mathrm{H}$, Tomita $\mathrm{H}$, et al. The effect of viscosity regulating dietary fiber for enteral nutrition against gastroesophageal reflux (in Japanese). $J$ JSPEN 1999; 14: 90-93.

12 Shimoyama Y, Kusano M, Kawamura O, et al. High-viscosity liquid meal accelerates gastric emptying. Neurogastroenterol Motil 2007; 19: 879-886.

13 Vela MF, Camacho-Lobato L, Srinivasan R, Tutuian R, Katz PO, Castell DO. Simultaneous intraesophageal impedance and $\mathrm{pH}$ measurement of acid and nonacid gastroesophageal reflux: effect of omeprazole. Gastroenterology
2001; 120: 1599-1606.

14 Sifrim D, Castell D, Dent J, Kahrilas PJ. Gastro-oesophageal reflux monitoring: review and consensus report on detection and definitions of acid, nonacid, and gas reflux. Gut 2004; 53: 1024-1031.

15 Higaki F, Yokota O, Ohishi M. Factors predictive of survival after percutaneous endoscopic gastrostomy in the elderly: is dementia really a risk factor? Am J Gastroenterol 2008; 103: 1011-1016.

16 Suyama Y, Adachi K, Notsu Y, et al. Efficacy of corrected rapid turnover protein increment index (CRII) for early detection of improvement of nutrition status in patients with malnutrition. J Clin Biochem Nutr 2009; 45: 44-48.

17 Tominaga N, Shimoda R, Iwakiri R, et al. Low serum albumin level is risk factor for patients with percutaneous endoscopic gastrostomy. Intern Med 2010; 49: 2283-2288.

18 Yoshida N. Inflammation and oxidative stress in gastroesophageal reflux disease. J Clin Biochem Nutr 2007; 40: 13-23.

19 Shimizu Y, Dobashi K, Mori M. Exhaled breath marker in asthma patients with gastroesophageal reflux disease. J Clin Biochem Nutr 2007; 41: 147153.

20 Fletcher J, Wirz A, Young J, Vallance R, McColl KE. Unbuffered highly acidic gastric juice exists at the gastroesophageal junction after a meal. Gastroenterology 2001; 121: 775-783.

21 Adachi K, Furuta K, Morita T, et al. Half-solidification of nutrient does not decrease gastro-esophageal reflux events in patients fed via percutaneous endoscopic gastrostomy. Clin Nutr 2009; 28: 648-651. 